\title{
GAME OF THRONES, INTERAÇÕES EM REDE E EXPERIÊNCIAS FORMATIVAS EM HISTÓRIA
}

\author{
Cristina D'Ávila \\ Edméa Santos \\ Társio Roberto Macedo
}

Resumo

O presente artigo evidencia um conjunto de argumentos teórico-metodológicos que explicitam a relação entre a série televisiva Game of Thrones, as interações em rede e as experiências formativas em História no contexto da cibercultura. Dialoga-se com referencial teórico-metodológico multirreferencial que interage com experiências hermenêutico-formativas, mediadas por meio de interações ciberculturais em rede e suas ressonâncias no conhecimento-formação em História. Os fenômenos experienciados no campo de pesquisa confirmam que as redes assimilam e trabalham com um potencial lúdico-formativo a partir da heterogeneidade dos imaginários aprendentes e suas sensibilidades quando se pretendem formações em História.

Palavras-chave: ensino de história; multirreferencialidade; formação; Game of Thrones; cibercultura.

\section{GAME OF THRONES, NETWORK INTERACTIONS AND FORMATIVE EXPERIENCES IN HISTORY}

Abstract

This article highlights a set of theoretical and methodological arguments that explain the relationship between the TV series Game of Thrones, network interactions and formative experiences in History in the context of cyberculture. We discuss the theoretical-methodological framework of the multi-referential that interacts with hermeneutic-formative experiences, mediated through cybercultural interactions in networks and their resonances in knowledge-formation in History. The phenomena experienced in the research field confirm that the networks assimilate and work with a playful-formative potential based on the heterogeneity of the imaginary learners and their sensibilities when training in History is sought.

Keywords: history teaching; multi-referentiality; training; Game of Thrones; cyberculture.

\section{JUEGO DE TRONOS, INTERACCIONES DE RED Y EXPERIENCIAS FORMATIVAS EN LA HISTORIA}

\section{Resumen}

Este artículo destaca un conjunto de argumentos teóricos y metodológicos que explican la relación entre la serie de televisión Game of Thrones, las interacciones de red y las experiencias formativas en Historia en el contexto de la cibercultura. El dialogo se establece con el marco teórico-metodológico del multirreferencial que interactúa con experiencias hermenéuticas formativas, mediadas a través de interacciones ciberculturales en redes y sus resonancias en la formación del conocimiento en Historia. Los fenómenos experimentados en el campo de la investigación confirman que las redes asimilan y trabajan con un potencial lúdicoformativo basado en la heterogeneidad de los alumnos imaginarios y sus sensibilidades cuando se busca capacitación en Historia.

Palabras clave: enseñanza de la historia; multirreferencialidad; formación; Juego de Tronos; cibercultura. 
DOI: https://doi.org/10.12957/teias.2020.48624

\section{INTRODUÇÃO}

O trabalho aqui apresentado tem como centralidade a compreensão de como emerge no campo das interações em rede, experiências hermenêutico-formativas, mediadas através das interações ciberculturais e suas ressonâncias no conhecimento-formação em História A conjunção de inspirações históricas que constrói o cenário da série televisiva Game of Thrones (Guerra dos Tronos) e suas interações em rede será o constructo com o qual trabalharemos.

Apesar da nossa pesquisa doutoral estar focada na interpretação de cenários/conteúdos histórico-fantásticos com um potencial lúdico-formativo através das interações em rede, imagino a projeção das contribuições heurísticas desta investigação para além do campo da didática em História e da formação de professores. Ou seja, a questão da interpretação com mediações via cibercultura, como potencial lúdico-formativo, é tratado aqui como uma possibilidade de transversalidade para todas as ciências, sobretudo as ciências humanas (história, geografia, sociologia, por exemplo). A escolha da narrativa histórica implica na facilidade heurística em relação a minha formação e competência como professor-pesquisador deste campo. Faz-se necessário ressaltar, que o histórico é transversal a qualquer compreensão das realidades humanas.

\section{APORTE TEÓRICO-EPISTEMOLÓGICO}

Temos a dizer, que dentro da prática da formação em história (mas não só), a hermenêutica como trabalho da interpretação tem um papel de grande importância a desempenhar nos processos de aprendizagem. Aliás, esse é um dos caminhos fundantes da aprendizagem humana. A partir do momento em que se narra um processo ou acontecimento histórico, este se encontra sujeito às mais diversas (consensuais e/ou conflituosas) subjetivações por parte das pessoas que os interpretam como esforço de compreensão implicada ${ }^{1}$, ou seja, base de uma aprendizagem significativa. A subjetividade dos sujeitos interpreta a história narrada a partir dos seus referenciais (significantes) e, assim, as narra também da maneira que a compreendem. Essa compreensão varia de acordo com as intencionalidades, intencionalidades essas que estão sujeitas ao que é mais importante em um acontecimento histórico, quem narra e como narra. É na intercrítica do exercício interpretativo que as "verdades" históricas podem emergir e construir aprendizagens qualificadas, portanto formativas.

Em Boaventura de Sousa Santos (1989, p. 13), temos que a reflexão hermenêutica tornase, assim, necessária para transformar a ciência, de um objeto estranho, distante e incomensurável com a nossa vida, num objeto familiar e próximo, que, falando uma língua própria, é capaz de nos comunicar as suas valências e os seus limites, os seus objetivos e o que realiza aquém e além deles, um objeto que, por falar, será mais adequadamente concebido numa relação eu-tu (a relação hermenêutica) de que numa relação eu-coisa (a relação epistemológica) e que, nessa medida, se transforma num parceiro de contemplação e da transformação do mundo.

A partir de Santos (1989), é possível compreender como uma abordagem históricoantropológica da tecnologia e da práxis humana, como fundamentos dos processos formativos e educacionais, podem contribuir sobremaneira para essa discussão. Lima Jr. e Hetkowski (2006, p. 29) trazem uma análise que muito nos interessa, quando diz que tecnologia é um processo que "[...]

\footnotetext{
1 A implicação é entendida como o processo pelo qual subjetivamos nossa relação com o mundo e, assim, nos vinculamos a tudo que nos envolvemos como experiência humana.
} 
DOI: https://doi.org/10.12957/teias.2020.48624

não se limita à assimilação e à reprodução dos modos de fazer (saber fazer) pré-determinados, estanques e definitivos". Nesse processo o homem usa do que está disponível ao seu redor para que possa alcançar objetivos. Assim, ele além de transformar a realidade da qual participa, transforma a si mesmo (LIMA JR., HETKOWSKI, 2006, p. 29-30).

Capurro (2010) reforça as afirmações anteriores ao analisar a reconstrução da hermenêutica, para um entendimento sobre a contemporaneidade. O desafio dos estudos hermenêuticos, de acordo com o autor, implica compreender as transformações que a sociedade do século XXI está envolvida, com o advento da cultura digital. Esse gênero de análise se coloca em um caminho distinto ao ato de extrair o sentido de um texto independentemente do ato de interpretar. Capurro (2010, p. 236) referencia-se nas ideias de Gadamer e Heidegger, para os quais interpretar é um ato inerente à existência do ser humano. Assim, o autor coloca que a bermenêutica digital se define no cruzamento entre o intérprete e os programas digitais, além da sua hibridação com os processos naturais e os produtos artificiais de seu contexto, desta maneira evidenciando o ser humano e sua relação com a máquina, como uma construção do mesmo e suas interpretações no centro da discussão.

A partir desse pressuposto, o ensino de História, e por consequência, a formação em história, via uma aprendizagem significativa, se depara com o desafio de mediar a compreensão para formandos inseridos em sua época, num contexto educacional, que, aliás, não os favorece. Para Tourinho (2004, p. 8) deve-se valorizar "A busca de caminhos teórico-metodológicos para a construção de um processo de ensino e aprendizagem que possibilite a cada envolvido com o ensino da história compreender-se como ser histórico e neste mesmo movimento (ou não) compreender a história".

Sobre o aspecto evidenciado por Tourinho (2004), podemos considerar que o fazer da ciência história está em fase de franca transformação. Hoje, nos primeiros anos do século XXI, cada vez mais a perspectiva de que uma obra de história é uma construção do próprio historiador, como dissemos anteriormente, se impõe: ele é quem escolhe o seu objeto, escolhe como vai trabalhá-lo, expô-lo, num abandono da crença positivista em uma possível neutralidade, pelo distanciamento entre o historiador e seu objeto de estudo.

Pensando assim, de acordo com Horn e Germinari (2006, p. 18), o ensinaraprender história não passa, em sua grande maioria, da perspectiva conservadora factualista que vivemos arraigados. Algumas características inerentes à escola brasileira atual como "[...] ênfase no escrito em oposição ao oral, individualismo no processo de aquisição do conhecimento e no produto apresentado, estrutura compartimentada e independente do conhecimento de quem aprende, desprezo pela vida diária e conhecimento do educando", mostra bem como a crítica desses autores pensam de modo congruente com o contexto que esse projeto pretende trabalhar dentro das suas possibilidades. Analisando com mais ênfase os argumentos contidos na última citação, temos como consequência a não disponibilidade de certos dispositivos que muitos estudantes têm como estruturantes para atividades voltadas para suas práticas lúdicas, diga-se de passagem, estruturantes da vida cotidiana e da sua aprendizagem-formação. Diariamente, pessoas utilizam dispositivos digitais para construir o seu tempo de lazer e seu tempo formativo. Crianças e jovens que nasceram com essas tecnologias acessíveis, os chamados geração polegarzinha (SERRES, 2013), podem aprender por experiências aprendentes outras, que mediadas pedagogicamente podem ser relevantes em termos educacionais e formativos.

De acordo com Arruda (2009, p. 10) "[...] vivemos a primazia do trabalho, e toda e qualquer atividade vinculada ao lazer ou ao ócio é desvalorizada socialmente". Ou seja, o lazer não nos 
formaria. Esse contexto nos mostra como é percebido com alguma frequência, de forma preconceituosa, os dispositivos digitais contemporâneos, como recursos afetivos e cognitivos. Vale a pena argumentar, que a ideia de dispositivo vinda das elaborações de Foucault, implicam em formas de construção que produzem ideias, corpos, situações, imaginações, poderes, configuram o que é visível e o que é dizível.

Com a complexidade e a importância formativa cada vez maior das múltiplas mídias em convergência, nota-se que existem possibilidades de utilizá-los para várias atividades, desde a formação para profissões, até na área do ensino e da prática de esportes. De acordo com Horn e Greminari (2006, p. 19), por exemplo, um material voltado para apenas a diversão e o ócio, visto a partir de uma ótica simplista, não seria passível de análise, discussão e uso em sala de aula e outros espaços/tempos de formação.

Desta forma, imaginamos que no processo multirreferencial de compreensão de narrativas com características históricas imbricados na cibercultura, percebe-se uma densidade importante de características culturais e especificidades hermenêuticas que podem ser usadas como dispositivo pedagógico para formação, a partir de uma perspectiva interpretacionista, bem como para um processo criativo realizado na produção de conteúdos, por exemplo. Essas mídias que se entrelaçam e se transformam nas suas apropriações culturais não seriam encarados como produtores de verdades tão somente, mas como dispositivos que vão possibilitar aos formandos (e formadores também!) uma aprendizagem compreensiva através de um meio que está bem próximo do seu tempoespaço, dos seus processos de imaginação, no sentido de uma implicação existencial cultural e política.

No caso específico da narrativa de Game of Thrones, possibilita aos receptores/ressignificadores uma noção mais ampla do cenário experienciado e das tramas com embasamento histórico. É mais um meio pelo qual o aprendente pode sentir-se inserido na história narrada, compreender o cotidiano dessas histórias e fazer contrastes da tomando posições em relação à atividade da qual participa.

Nestes termos, essas mídias hyperlinkadas são consideradas potencializadoras de alguma aprendizagem significativa, ou seja, que produzem significantes social e educacionalmente relevantes. Neste veio, a experiência com a narrativa de Game of Thrones entra de forma potencial no campo do que podemos considerar uma aprendizagem qualificada, portanto formativa, já que, segundo Macedo (2010), a formação, que tem a aprendizagem significativa qualificada como seu principal subsídio, é uma experiência irredutível que deve emergir sempre interpretada, valorada, discutida, do contrário não é formação.

Os argumentos que se constroem nesse trabalho se fundamentam na ideia de que, para compreender a criação enquanto imperativo da vida inteligente, esta precisa sempre se reconstruir sem cessar, a cada momento, pois o fenômeno hermenêutico da construção de saberes históricos se constitui como uma experiência fulcral. Nesses termos, procura-se apropriar do argumento de Galeffi (2014) para assumir que será imperativo compreender o ato criador de maneira "própria e apropriada", lançando-nos na aventura do conhecimento e do desconhecimento de mim, do Outro e do que nos implica no mundo da construção de narrativas em rede, potencializadoras de uma formação em História.

\section{OS DISPOSITIVOS DE PESQUISA}


Acerca da série televisiva Game of Thrones, de suas especificidades narrativas e potencialidades lúdico-formativas, temos a dizer que a adoção desse complexo interacional advém do nosso interesse pela cultura contemporânea mediada por tecnologias digitais em rede no ciberespaço e nas cidades (SANTOS, 2011) como possibilidade para se trabalhar por uma hermenêutica e uma heurística contemporâneas na formação. A cibercultura permeia parte considerável da sociedade, partindo da constatação de que o digital se relaciona de forma ubíqua a todo o espaço urbano na atualidade e Game of Thrones é um fenômeno midiático que desperta interesse não somente no âmbito do entretenimento, como no âmbito formacional-educacional.

O seriado que se encerrou no ano de 2019 se baseou na série de livros intitulados $A$ Song of Ice and Fire (traduzido para o português como Crônicas de Gelo e Fogo) publicado a partir de 1996, pelo escritor americano George R. R. Martin. A série televisiva teve oito temporadas, lançadas mundialmente pela rede de televisão $\mathrm{HBO}$.

Um dos aspectos mais evidenciados na trama são as disputas, por vezes violentas, entre as famílias mais poderosas de $W_{e s t e r o s}{ }^{2}$ pelo controle dos Sete Reinos ${ }^{3}$. A saga se aproxima do que Jacques Le Goff (2008) chama de "Idade Média má", quando a violência fazia parte da vida das famílias de todas as classes, desde a nobreza e suas intrigas palacianas, até os camponeses que compunham a linha de frente dos exércitos dos senhores em guerra.

Os arranjos entre famílias através do matrimônio, as traições, e as lutas por territórios da Idade Média contribuíram para a concepção de narrativa que Martin (2010) utiliza em seus livros.

Contextualização, explicitação política e realce/valorização de uma história que se realiza num contexto de proximidade das problemáticas históricas inerentes à vida social historicamente situada, emergem como princípios que fundam a dinâmica pedagógica do Game of Thrones.

A conjugação das características da narrativa com os aspectos que constroem as características da pesquisa deste projeto só fazem agregar mais robustez heurística ao nosso objeto de investigação, na medida em que se trata de uma narrativa contemporânea eivada de evidentes potencialidades formativas quando possibilita visões outras da história e uma discussão descentrada da perspectiva factual, o que instiga o imaginário interpretativo como fonte de saberes generativos.

\section{RELAÇÕES ENTRE TECNOLOGIAS DIGITAIS E EDUCAÇÃO}

Diante do contexto cibercultural em que vivemos, o professor, ao utilizar tecnologias digitais para experimentá-las e experienciá-las em seus contextos de atuação, como dispositivos com potencialidades para uma determinada formação, assume, de acordo com as ideias de Cravo, Cassal e Silva (2012), uma atitude inovadora tanto na maneira de aprender, enquanto usuário desses dispositivos, quanto na forma de mediar a formação, em suas práticas pedagógicas.

Pensando no processo formativo docente, entendemos que é nesse processo de construção e tradução de mídias, por meio de interações polissêmicas, que pode estar a importância da potência lúdico-formativa que perspectivamos. É justamente nesse ponto que professores podem encontrar potencialidades para ressignificar suas práticas. Se partimos do pressuposto de que a formação pode ocorrer em um processo multirreferencial de compreensão via interações em rede, entendemos que o ponto de partida desta pesquisa é pensar como se constrói esse processo

\footnotetext{
2 Continente fictício onde a trama começa.

${ }^{3}$ Liga formada pelos principais reinos de Westeros.
} 
formativo de professores, em termos hermenêuticos, pelas diversas narrativas que constituem um pensar em rede.

A partir das ideias de Cravo, Cassal e Silva (2012) entendemos que o trabalho dos profissionais da educação implica a construção e reconstrução constante do seu papel diante da sociedade que os forma e que se transforma. Essa, definitivamente, não é uma tarefa fácil. É um trabalho que prima pelo movimento, pela saída da zona de conforto de muitos docentes. Bonilla (2005) e suas ideias, por exemplo, permitem entender que somente pela abertura à ressignificação será possível criar possibilidades para que as transformações em nosso sistema educacional emerjam dentro dele próprio, em conjunção com as transformações sociais do nosso tempo. Assim, podemos criar estratégias para que professores consigam transpor os paradigmas existentes e vislumbrem dispositivos de mediação para o uso crítico-heurístico das mídias, possibilitando ao estudante o exercício de seu potencial formativo pela construção intercrítica de saberes.

Apesar de toda a resistência de uma instituição que, de acordo com Bonilla (2005), ainda se mostra embasada em noção geral de reprodução e transmissão de um modelo hegemônico, fechada à exterioridade, o formando (ator de seu tempo e, por conseguinte, questionador de toda filosofia tradicionalista-tecnicista da educação), que antes devia obediência quase que restrita ao professor, encontra-se relativamente no mesmo nível, em termos de disponibilização da informação.

A geração que nasceu em meio a essa cultura, depois da década de 1980, tratando-se do contexto brasileiro, em maioria, tem como cultural o hábito de afirmar suas preferências, tanto no campo das mídias quanto em outros campos, incluindo aí o fazer escolar. Dialogando com as ideias de Amaral (2015, p. 142), entende-se que essa cultura tem relação forte com o que a autora denomina como "ativismo de fã". Essa concepção, que pretende problematizar a construída divisão entre os mundos do consumo e da cidadania, vem sendo viabilizada graças à aprendizagem com práticas de consumo da "cultura dos fãs", da qual destacamos o compartilhamento de material fanmade (feito por fãs) em movimentos sociais.

Algo assim mostra-se contraditório nestes termos, quando encaramos o contexto da educação nacional, ainda dotado de uma cultura ligada às ideias de eficiência e estandartização de currículos e métodos de ensino, cultivados num tipo de interatividade de pouco alcance e de restritas possibilidades de se defrontar com a diferença, potencializados pelo mundo virtual.

A partir do momento em que as relações entre professor e aluno, em termos de disponibilização da informação e das interpretações, entram em patamares de relativa igualdade de condições, muitos fatores se modificam. Narrativas carregadas de conteúdo histórico de possibilidades hermenêuticas podem trazer para o aluno informações e provocações significativas para o contexto da sala de aula em termos do exercício interpretativo, tão reclamado pelas avaliações da nossa educação. Podemos dizer a mesma coisa em relação às estéticas imagéticoverbais dos quadrinhos e das séries televisivas. Temos aqui realçada a pertinência das inquietações de Adichie (2010) sobre os perigos e a necessidade de superar a ideia de "história única".

É neste cenário que a formação de professores se torna uma problemática concreta, na medida em que as instituições nas quais atuam e se formam, em grande medida, desconhecem a dinâmica "singular e singularizante" (MACEDO, 2000) das interações hyperlinkadas em rede em processos formativos.

Diante deste cenário formativo de inovações e rupturas, uma questão que consideramos fundante emerge para o trabalho que realizamos: como emergem, em termos compreensivos, experiências hermenêutico-criativas como processos potencialmente lúdico-formativos de 
DOI: https://doi.org/10.12957/teias.2020.48624

professores de história, tendo como dispositivos a difusão e a mediação das interações em rede, a partir das narrativas de Game of Thrones?

Seguindo este questionamento, temos como objetivo compreender como se configuram as experiências hermenêutico-criativas como processos formativos de professores, tendo como dispositivos e mediadores narrativas históricas em rede, que configuram a obra Game of Thrones, num cenário de formação docente.

\section{O CAMPO}

Para analisar o campo da nossa pesquisa, que trata do potencial lúdico-formativo da série Game of Thrones, pelas relações desta mídia com processos históricos, a perspectiva dos seis indicadores analíticos que Bruyn (1966) apresenta é central para avançar no entendimento das compreensões realizadas durante o processo de observação. Esses indicadores foram utilizados para alcançar uma "adequação subjetiva” à questão proposta na pesquisa.

Acerca do tempo, tentamos investi-lo no campo de análise, observando as ações dos atores sociais nos campos formais e informais da coleta de informações consideradas pertinentes. Os atores falaram sobre os conteúdos produzidos e selecionados para essa pesquisa com intensidade próxima a outras referências, como filmes, games e desenhos animados.

Quantos aos lugares nos quais se atualizam as ações, pudemos realçar algumas das práticas dos atores, no que se refere à relação entre conteúdos produzidos no Youtube, nesse caso sobre Game of Thrones, a História no canal Nerdologia e a formação histórica. No espaço da rede, no qual grande parte da formalidade é despida pelo ordinário do cotidiano, observamos que as práticas relacionadas à formação histórica desses sujeitos, em diversas matrizes, constroem suas compreensões sobre História por meio de referenciais ciberculturais, com características históricas.

Para as circunstâncias sociais, fez-se necessário viver algumas das circunstâncias que o grupo experiencia. Nossa implicação com o trabalho ajudou sobremaneira a identificar e compreender essas circunstâncias. Principalmente no caso dessa pesquisa, quando estivemos em situação semelhante, como fãs e pesquisadores, que viam nos espaços ciberculturais espaçostempos possíveis de formação - um potencial que, em geral, não é trabalhado pelos professores em suas escolas.

Em termos de linguagem, a proximidade com a que foi utilizada pelos atores teve grande importância para a compreensão de suas falas. Muito do que esses estudantes trazem construção de sua linguagem provém da maneira de agir nas redes sociais, linguagem essa com que se convive cotidianamente, enquanto entusiastas da série.

A proximidade constituiu-se a partir do momento da identificação de gostos parecidos entre os atores e pesquisadores. Nesses termos, sentimo-nos seguros para compreender os sentidos e significados e as narrativas configuradas.

O último indicador, o de consenso social, se constituiu no processo de aproximação e imersão na cultura. Entende-se que esse último indicador é excessivamente funcionalista se, no mundo das compreensões e interpretações, não só existem consensos em processo de estabilização: conflitos, paradoxos, ambivalências, contradições, incertezas, derivas fazem parte, também, desse cenário e foram evidenciados pelas diferentes concepções de valoração da experiência por meio das narrativas dos interatores.

Nesse ponto, quando as compreensões dos interatores em rede se encontram com as nossas compreensões, pensa-se numa pedagogia sobre o potencial lúdico-formativo dos conteídos produridos em rede, em História. 
DOI: https://doi.org/10.12957/teias.2020.48624

Entendemos que a sensibilidade aprende, assim como se aprende pela sensibilidade. Portanto, a suposta cisão entre razão e sensibilidade encontrada enquanto discurso comum entre educadores nos sensibilizou, a partir dos fenômenos do campo, assim como ao ser pautado pelos argumentos de D’Ávila (2016), em busca de subsídios teóricos que pudessem sustentar a ideia de uma formação para o sensível, voltada para a compreensão dos processos subjetivos que subjazem as ações humanas cotidianas e que estão presentes, também, nas ações do ensinar e do aprender.

Sustentamos neste argumento a premissa de que não há aprendizagem sem sensibilidade, assim como não há razão sem sensibilidade e vice-versa. Das experiências que nos trouxeram até aqui, temos constatado que aquelas com potencial formativo são as que provêm de experiências que integram o pensar, o sentir e o agir humanos. O que reforça, de acordo com D'Ávila (2016), antigo provérbio chinês: "Diga-me, e eu esquecerei; ensine-me, e eu lembrarei; envolva-me, e eu aprenderei".

A partir dos argumentos da autora, compreendemos que um processo formacional sensível é aquele que tem o potencial de oferecer aos sujeitos da aprendizagem a compreensão do mundo, sem perda de visão de uma perspectiva global; sem perda tampouco da sensibilidade fundamentos considerados importantes ao processo de construção do conhecimento. Pela fala de um dos interatores presentes na pesquisa de Macedo $(2020)^{4}$, pensamos uma formação que traga em sua gênese uma intervenção didático-formacional sensível, aguçando, para além da inteligibilidade, a estesia, a estética e o componente lúdico, a partir das interações em rede envolvendo relações entre eventos históricos e narrativas de séries televisivas como Game of Thrones.

Nesses termos, Mafesoli (2005, p. 69) afirma que tudo que é da ordem da paixão deverá servir como motor para a compreensão dos fenômenos societais, visto que é inevitável se conceber uma outra epistemologia não mais centralizada sobre a razão abstrata, mas sobre a razão sensível: "Em uma palavra, compreender que a racionalidade aberta integra seu contrário, e que é de sua conjunção que nasce toda a apreensão global”. =

Assim, o potencial lúdico-formativo nasce justamente dessa "razão interna" que amplia a consciência como um processo epistemológico capaz de apreender a globalidade social no todo e em suas partes constituintes. É importante ressaltar que o autor não fala em negar o pensamento moderno. O que se propõe é um alargamento da consciência, ampliando a compreensão de domínios até então invalidados pela lógica moderna: os caminhos do não racional, do não lógico, que se tornam caminhos de ou de outra racionalidade, de uma outra lógica. Talvez melhor expressos como racionalidade outra, lógica outra, porquanto traz consigo a diferença e a alter-ação, ou seja, ação com o outro.

O pensamento orgânico em Mafesoli (2005) também é muito caro a partir do momento em que o autor nos diz que o cotidiano é constituído de múltiplas experiências com forte carga erótica, ou seja, carregada de emoções e afetos. São essas paixões que movem a organização das relações sociais e, por consequência, as relações formacionais.

\section{CONCLUSÃO}

A partir dessa discussão e das interações obtidas e analisadas, compreendemos que a estética ambiental da série envolve os espectadores, mobilizando-os ao emitirem suas opiniões e

\footnotetext{
${ }^{4}$ Opa, peraí! Se seguirem o que aconteceu na guerra das rosas, já dá pra ter uma ideia de como terminará Game Of Thrones. É provável que Jon Snow derrote Circei Lannister, e unifique Westeros sob seu domínio. Ele e Danerys lutam e, por fim, se casam, dando início à Dinastia do Gelo e do Fogo, que seria o equivalente à Dinastia Tudors.
} 
ao participarem de grupos de debate sobre seus temas favoritos. Dessa forma, tanto a rica produção da série quanto a qualificada produção do Nerdologia atraem esses fãs para os debates sobre história e cultura pop nesses espaços.

É justamente nessa estética ambiental, nesses ambientes digitais de interação imersivos, que ocorrem interações de forma hiperlinkada com potenciais lúdico-formativos em História, visto que se trata de uma narrativa fantástica que carrega fortes elementos do ambiente de épocas históricas que de fato existiram e que, inclusive, serviram de inspiração para a construção dessas narrativas fantásticas ${ }^{5}$.

O movimento audiovisual produz maior índice de atenção e prazer, a partir do momento em que elementos, basicamente do imaginário popular, ganham materialidade. Mitos, dragões, gigantes e outras criaturas fantásticas povoaram as mentalidades durante séculos. Com o advento dos efeitos especiais e depois da computação gráfica, esses entes que somente povoavam o imaginário popular puderam ser vistos e compreendidos historicamente através das animações, dos cinemas e, no nosso estudo, nas séries de TV e nas redes sociais.

O movimento de sensibilização a partir da identificação com as tramas de determinados personagens é pertinente no estudo desde o momento em que os interatores se posicionam contra ou a favor das decisões do roteiro, dos caminhos seguidos pelos personagens e, sobretudo, quando tentam de alguma forma relacionar os personagens da ficção com atores históricos, mesmo que para além do conteúdo trazido pelo Nerdologia, ou até mesmo da pertinência histórica, como evidenciamos nos argumentos de Macedo (2020) ${ }^{6}$.

Uma série com tantas inspirações históricas, mesmo sendo uma narrativa fantástica, também produz emoções "históricas", sensações desiderativas no público que assiste e comenta nas redes digitais.

Isso nos remete, dialogando com o pensamento de D’Ávila (2016), a compreensão de que dispomos sempre, nos processos de ensino, dos saberes experienciais de que são portadores os estudantes e que, apesar não terem vez nem lugar na escola, na perspectiva do currículo engessador que temos atualmente, entram nos espaços escolares "sem pedir licença". Um saber dito "popular" abrange formas sensíveis e inteligências singulares para interpretar o mundo, as quais foram renegadas durante séculos na escola, em nome de um saber genérico, universalizante e elitista, ou seja, em prol de uma razão abstrata e instrumentalizadora.

Podemos afirmar, a partir dos fenômenos experienciados no campo da pesquisa realizada, que o inteligível é o conhecimento abstratamente articulado pelo cérebro que mobiliza signos lógicos e racionais, e que a sensibilidade se refere à sabedoria do corpo e manifesta-se em diversas situações da vida corrente, entre elas, as dinâmicas do social em redes ciberculturais.

Enfim, a ideia é que as redes assimilam e trabalham com um potencial lúdico-formativo a partir da heterogeneidade dos imaginários aprendentes e de suas sensibilidades, quando se pretendem formações em História com produções de conteúdo, nesses espaços.

\section{REFERÊNCIAS}

\footnotetext{
${ }^{5}$ Meu Deus, o mapa de Game of Thrones é muito parecido com o das ilhas britânicas com a Irlanda [embaixo]. Meu Deus, como nunca reparei antes?? Mind explosion!!!

${ }^{6} \mathrm{E}$ o fim de GOT poderia talvez ser um paralelo com a transição da casa Tudor para a casa Stuart, com Bran sendo tipo o rei James Stuart da Escócia?
} 
ADICHIE, Chimamanda. O perigo da história única. Disponível em: http://migre.me/uDFLk. Filmado em julho de 2009, postado em out. 2009. Acesso em abr. 2010.

AMARAL, Adriana; SOUZA, Rosana; MONTEIRO, Camila. De Westeros no \#vemprarua à shippagem do beijo gay na TV brasileira. Ativismo de fãs: conceitos, resistências e práticas na cultura digital. Galaxia. São Paulo, online, n. 29, p. 141-154, jun. 2015.

ARRUDA, Eucído. Jogos digitais e aprendizagens: o jogo Age of Empires III desenvolve ideias e raciocínios históricos de jovens jogadores? Tese de Doutorado. Minas Gerais, UFMG, 2009.

ATLAN, Henri. Com razão ou sem ela: intercrítica da ciência e do mito. Tradução de Fátima Gaspar e Fernando Gaspar. Lisboa: Instituto Piaget, 1994.

BARBIER, René. A pesquisa-ação. Tradução de Lucie Didio. Brasília: Liber Livro, 2004.

BARBOSA, Joaquim. O diário de pesquisa: o estudante universitário e seu processo formativo. Brasília: Liber Livro, 2010.

BONILLA, Maria Helena. A práxis pedagógica presente e futura e os conceitos de verdade e realidade frente às crises do conhecimento científico no século XX. In: PRETTO, Nelson De Luca. Tecnologias e novas educações. Salvador: EDUFBA, 2005. p. 70-81.

CAPURRO, Rafael. La hermenéutica frente al desafío de la técnica digital. Liinc em Revista, v. 6, n. 2, setembro, 2010, Rio de Janeiro, p. 235-249.

CRAVO, Ana Cristina; CASSAL, Ana Elisa e SILVA, Eli. Cultura da convergência: desafios de ser professor na era das mídias. $4^{\circ}$ Simpósio Hipertexto e Tecnologias na Educação. UFRGS, 2012.

COUTO, Edvaldo. A infância e o brincar na cultura digital. Perspectiva, Florianópolis, v. 31, n. 3, 897-916, set./dez. 2013.

D’ÁVILA, Cristina. Razão e sensibilidade na docência universitária. Em Aberto, Brasília, v. 29, n. 97, p. 103-118, set./dez. 2016.

GALEFFI, Dante; MACEDO, Roberto Sidnei; BARBOSA, Joaquim. Criação e devir em formação: mais-vida na educação. Salvador: EDUFBA, 2014.

GAME of Thrones: RPG. Desenvolvedora: Cyanide Studio. Publicadora: Focus Home Interactive. França, 2012.

GEERTZ, Clifford. A interpretação das culturas. Rio de Janeiro: Zahar, 1989.

HORN, Geraldo.; GERMINARI, Geyco. O ensino de História e seu currículo: teoria e método. Petrópolis, Rio de Janeiro: Vozes, 2006.

LE GOFF, Jacques. Uma longa Idade Média. Rio de Janeiro: Civilização Brasileira, 2008.

LIMA JR, Arnaud; HETKOWSKI, Tânia Maria. Educação e Contemporaneidade: por uma abordagem histórico-antropológica da tecnologia e da práxis humana como fundamentos dos processos formativos e educacionais. In: LIMA JR, Arnaud S; HETKOWSKI, Tânia (orgs.). Educação e contemporaneidade: desafios para a pesquisa e a pós-graduação. Rio de Janeiro: Quartet, 2006. p. 29-46.

MACEDO, Roberto Sidnei. Etnopesquisa crítica e multirreferencial. Salvador: EDUFBA, 2000. 
MACEDO, Roberto Sidnei. Etnopesquisa crítica, etnopesquisa-formação. Brasília: Liber Livro, 2010.

MACEDO, Társio. Experiências formativas em história no YouTube inspiradas na série televisiva Game of Thrones. Tese de Doutorado. Salvador, FACED-UFBA, 2020.

MACEDO, Társio; MELO, Sócrates. RPG e educação: uma abordagem histórica. Feira de Santana, UEFS, 2009. (mimeo).

MAFFESOLI, Michel. Éloge de la raison sensible. Paris: La Table Ronde, [1996] 2005.

MARTIN, George. A Guerra dos Tronos: Crônicas do gelo e fogo (livro 1). São Paulo: Leya, 2010.

RICOEUR, Paul. O conflito das interpretações: ensaios de hermenêutica. Rio de Janeiro: Imago, 1978.

SANTOS, Boaventura de Sousa. Introdução a uma ciência pós-moderna. Rio de Janeiro: Graal, 1989.

SANTOS, Edmea. Pesquisa-formação na cibercultura. Santo Tirso: Whitebooks, 2014.

TOURINHO, Maria Antonieta. O ensino de história: inventos e contratempos. Tese de Doutorado. Salvador, FACED-UFBA, 2004.

Submetido em outubro de 2019. Aprovado em janeiro de 2020.

\section{Informações do(as) autor(as)}

Cristina D’Ávila

Prof ${ }^{a}$. Titular PPGE / FACED. (UFBA).

E-mail: cristdavila@gmail.com

ORCID: http://orcid.org/0000-0001-5946-9178

Link Lattes: http://lattes.cnpq.br/2584950986779890

Edméa Santos

Prof ${ }^{a}$. Titular-livre da Universidade Federal Rural do Rio de Janeiro (UFRRJ).

E-mail: edmeabaiana@gmail.com

ORCID: http://orcid.org/0000-0003-4978-9818

Link Lattes: http://lattes.cnpq.br/4023554724278836

Társio Roberto Macedo

Doutorando PPGE / FACED-UFBA

E-mail: tarsio.hist@gmail.com

ORCID: https://orcid.org/0000-0001-5138-6968

Link Lattes: http://lattes.cnpq.br/4199861757137149 